\title{
The Bystander Effect of Trekking Tourism: Proposing a Typology of Environmental Ideal Types
}

\author{
Martin Trandberg Jensen \\ martinjensen 123@gmail.com
}

\begin{abstract}
Tourism impacts in fragile nature-based environments have repeatedly been investigated from a wide array of academic viewpoints. However, in order to improve future researches that aim at measuring and/or elaborating on the pro-environmental awareness and behavioral patterns of trekking tourists, it is of utmost importance to identify the present environmental ideal types of trekkers. This research sets out to create an environmental typology of international trekkers visiting the Annapurna Conservation Area in Nepal. This research was conducted in between February-August, 2010, and included an extensive three-month ethnographic fieldwork within the conservation area, applying quantitative and qualitative techniques in order to create a framework of environmental trekking rationalities.

A preliminary comparative analysis shows that trekkers seem to perceive themselves as more pro-environmental when trekking in Nepal compared to when at home. There appears to be a 'selective optimistic self-perception' among trekking tourists that creates a discrepancy between environmental self-perception and actual behavior. This research argues that trekkers seem to be locked into unsustainable consumption patterns, characterized by the constant strive toward Western comforts and commodities. In order to illustrate this case, the following article presents a novel typology that defines a number of different environmental ideal types within trekking.
\end{abstract}

Keywords: Theory of Planned Behavior; Value-Action Gap; Bystander-Effect; Model of Responsible Environmental Behavior; Psychological Discrepancy; Environmental Ideal Typing; Typology

\section{Introduction}

Mountains, with their remote and majestic beauty, are among the most popular destinations for ecotourism, and mountain tourism can be a key factor in the focal concern for both the overall improvement in people's quality of life through sustainable development initiatives in economic development and environmental development. In both socio-economic and environmental terms, tourism in mountain regions is a mixed blessing; it can be a source of problems, but also offers many opportunities (Sanjay, K., 2002, p. 38). 
In Nepal, such development has taken the form of trekking, often described by those practicing or commercializing it as eco-tourism, which once and again is presented as a sustainable tourism form that makes up a positive alternative to mass tourism consumption (Sacareau, 2009; Fennel, 2000). Based on this perspective, it is not a bold statement to argue that trekking tourism can be considered a rather ideal example of sustainable tourism. Relating this to Nepal, it is even reinforced by authors stating that trekking tourism in Nepal is one of the foremost examples of ecotourism operations (Gurung \& DeCoursey, 1994). However, as the introductory citation states, mountain tourism is connected to a mixed blessing that can similarly be seen as the centrifugal axis of this research.

\section{Trekking and environmental issues}

Trekking has been allowed in Nepal since 1964 when the Nepalese government first allowed foreign visitors to make multi-day hiking tours (Stevens, 2003) and in connection to the country's diverse geographical features, adventure and trekking tourism were seen as viable strategies for rural development (Zurick, 1992). Mountain-related tourism activities are undoubtedly the core of tourism in Nepal, and around 43 percent of all international arrivals participate in trekking (MCTA, 2004). This fact alone indicates that it is of utmost importance to manage this sector with a delicate economical, social and environmental balance in mind.

Nowadays, tourism has brought major changes to the Nepal environment, which has altered traditional patterns of natural land and resource management and put increasing pressure on the general environment. According to Stevens (2003), diverse regionally varying linkages have been suggested between tourism and changing forest use; community management of forest and grazing; the local accumulation of rubbish and pollution from human waste, forest degradation and damage to alpine vegetation.

As a mountain destination experiences higher density of tourism development, the potential for conflict between maintaining a healthy natural environment and economic development also increases. This has urged planners and decisionmakers to devise and adopt innovative approaches that seek to strike a balance between tourism (economic) development and nature conservation in the mountains Sanjay, K. (2000, p. 662).

This research presents a fundamental environmental typology which is regarded as a valuable tool for all actors within the Nepalese tourism sector that wish to increase their understanding of trekking tourists in connection to proenvironmental perceptions and beliefs. 


\section{Presenting the methods}

\section{Why the ethnographic approach?}

A large number of research and accounts from various decades identify trekking in Nepal as a key cause to negative environmental impacts (Mishra, 1973; Garratt, 1981; Zurick, 1992; Sanjay, 2002). This research's literature review indicates that the primary design of existing environmental research is based on quantitative impact studies. That is, comparative statistical studies elaborating on past vs. present environmental numbers and figures. Although researches have been conducted from a host-perspective (Zurick, 1992; Nyaupane \& Thapa, 2006), there seems to be insufficient research from the guest's perspective. This lack of research became a main driver for conducting this research from the trekker's perspective. Within adventure tourism, Weber (2001) and Beedie \& Hudson (2003) both suggest that academic research on individual's subjective experience and perception are under-researched. In the Nepalese context, Musa et al. (2004) and Pandey (1994) argue that there is an apparent neglect in researching the attitudes and needs of trekkers in Nepal. On the basis of this apparent absence of academic knowledge, the objective of this research is to shed light upon the environmental awareness and attitudes of international trekkers visiting Nepal from a first-hand ethnographic perspective.

\section{Study site and period}

The formal research was undertaken from February to August 2010, with the fieldwork ranging from April-June. However, before the start of the research a wide-ranging literature and destination review was undertaken. The fieldwork took place in the Annapurna Conservation Area, which also makes up the geographical limitation of the research.

\section{Sampling strategy}

Marshall \& Rosmann (1995) argue that a qualitative research should explicitly describe its procedures and criteria for the research sampling. The primary information of this research is based on 87 completed surveys and 22 individuals as well as group interviews. In total, 43 respondents participated in the interviews. Both data collection processes have been based on the 'convenience sampling strategy' (Miles \& Huberman, 1994) which is primarily based on the time and cost constraints of the research. Furthermore, since the research aimed at approaching trekkers during the trek, there was the constant chance that respondents would move. Hence, the researcher found it necessary to 'strike while the iron was hot' and approach respondents when the chance for an interview/survey would be there (during short breaks, acclimatization days, dinner times etc.). 


\section{Questionnaire design}

The final questionnaire is based upon two existing frameworks which have been applied in similar studies (Özden, 2008; Miller et al., 2007). The questionnaire is applied because it fits with the theoretical review as presented in the following discussion of this article. It is made up of 30 environmental statements (Özden, 2008) which respondents reply upon based on a 5-point Likert scale. Finally, the questionnaire applies a minor segmentation typology (Miller et al., 2007) which is used to create an early comparative analysis. This part of the questionnaire asks respondents to choose one sentence that fit their environmental beliefs the most (1) At home and (2) While trekking.

\section{Log observations}

An indispensable part of the study of any social institution, wherever this can be obtained, is deliberate and sustained personal observation of its actual operation (Dingwall, 1997). There seems to be a general academic acceptance that ethnography originates from anthropology and therefore often relates to observation studies (Gellner \& Hirsch, 2001). This is also the case in this research in which the method of doing 'log observations' is based upon the researcher's visual accounts which were documented through audio records as the fieldwork progressed.

\section{Contextualizing the theories for research application}

Within the academic world, the idea of environmental awareness has grown steadily since the 1970 s and during the 1980 s people have come to understand that it is imperative to protect the environment (Amendah and Park, 2008). This green ideology is also supported by the massive number of academic articles which put focus on environmental issues, per se, and in connection to adventure tourism (Beedie \& Hudson, 2003; Bhattarai, et al., 2005; Lee \& Moscardo, 2005; Korhonen \& Lappalainen, 2004; Miller et al., 2010; Moisander, 2007; Musa et al., 2004; Nyaupane \& Chhetri, 2009; Nyupane \& Thapa, 2006; Sacareau, 2009; Sanjay, 2000; Stevens, 2003; Williams \& Soutar, 2009; Zurick, 1992; Özden, 2008). From this perspective, it is reasonable to argue that environmental issues in tourism represent a hot topic in present academic literature. In connection to this hot topic, Luo \& Deng (2008) argue that a recent tendency shows that researchers are increasingly interested in segmenting eco-tourists by their social or environmental value. This is interesting to this research because the pure concept of trekking is often linked with an ecological and nature-based paradigm (Gurung \& DeCoursey, 1994; Musa et al., 2004; Sanjay, 2002) which would eventually indicate that this research is in line with a present trend in tourism literature - in this case, segmenting and profiling trekkers by their environmental values. However, it was difficult to find a fitting theoretical construction that could be applied to do more than merely focus on knowledge based variables, 
which can be seen as simple quantitative measurements of people's awareness of an issue.

A theoretical basis which manages to capture the complex notion of environmental awareness is found in a newly conducted study by Lee \& Moscardo (2005) who investigated the impacts of ecotourism experiences on tourist's environmental attitudes and behavioral intentions. This research proposes an interesting framework by putting together elements from the theory of planned behavior and the model of responsible environmental behavior (Hines et al., 1986) to create a theoretical notion of what makes up environmental behavior. The model as illustrated below makes up the applied theoretical basis of this research.

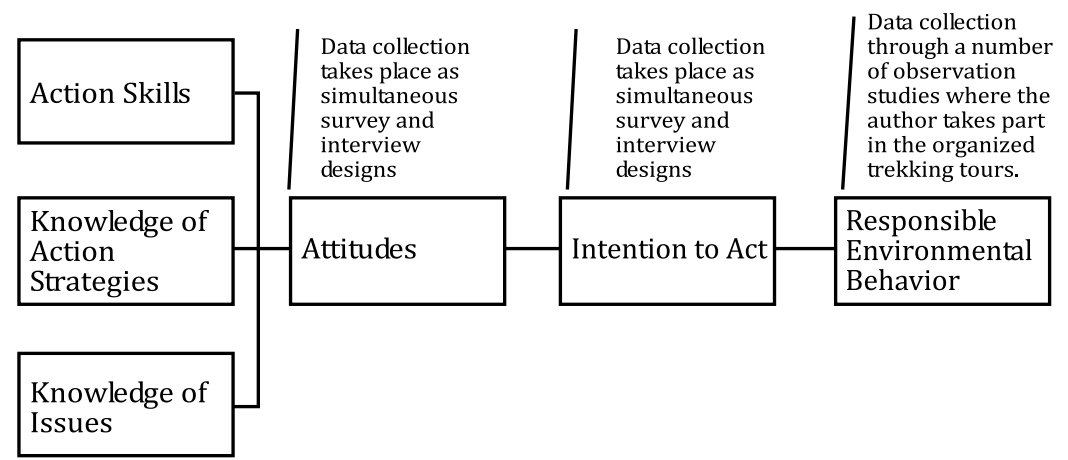

Figure 1: A simple framework for understanding responsible environmental behavior

(Adopted by Lee \& Moscardo, 2005)

As applied in this research, the practical use of this model is primarily focused on the boxes 'Attitudes', 'Intentions to Act' and 'Responsible Environmental Behavior'. The linear way in which the boxes are presented should not be regarded as the way this research undertook its data collection. Rather, the researcher stresses that this is simply a plain illustration of the major issues of the research. In terms of extracting data in connection to the issues of 'attitudes' and 'intentions to act', the tools of survey and interview studies were applied. In order to elaborate upon 'responsible environmental behavior' the research used log observations to account (mis)matches between stated trekking attitudes and intentions and actual behavior.

\section{Presenting the findings - A comparative analysis}

I think I am more aware when I trek, 'cause when you are home you just have habits, and it's hard to break, and you do what everyone else does, but when you are trekking, you're...for me I am in nature and I think a lot about what I do 'cause it seems, you are in new situations so you have to see everything in a new way, and you can make a choice more than you can at home with all your habits. 
The upper statement derives from an inexperienced Danish trekker who had just started his trek when the interview was conducted. Nevertheless, his quote presents a central and pivotal part of the reason for behaving differently while 'at home' and while trekking in Nepal. NCC \& SDC (2006) concludes something very similar about sustainable consumption arguing that people often find themselves locked in to consumption patterns that are not sustainable when they are in their everyday environment.

During the field research, it became clear that whether or not people actually behave differently is something which is extremely hard to conclude upon because it is a matter of respondent answers and the reliability of these answers. An issue which Jackson (2005, part 1, p. 5) stressed in a similar research; 'For social and behavioral issues, the problem is compounded by the subjective nature of the evidence base'. As one elderly American trekker precisely puts it when asked if trekkers are as green as they think they are: "Yeah, in the main I think they are emotionally as green as they think they are. Whether or not that translates into reality is another question". In order to elaborate further on this matter, the research constructed an early comparative analysis that proposes some general environmental characteristics of trekkers.

\section{I will if you will}

During the fieldwork interviews, the primary denominators for environmental problems were often encapsulated by the use of words like 'plastic' and 'rubbish'. The research identifies that those trekkers who perceive themselves as environmentally aware instinctively connect this to not overusing the natural resources and not throwing waste. Although it is better than showing no awareness, it might also constitute an inappropriate frame of reference. Similarly, NCC \& SDC (2006) argue that the arrival of recycling bins on people's doorsteps helps people take environmental actions, but also dominates their perception of pro-environmentalism to such an extent that people struggle to think about other ways in which they can make a difference. However, although the presence of plastic and rubbish might be the early starting point for proenvironmental idealism, the presence of garbage may also create a rather inappropriate effect in trekking behavior.

Uhm, when I trek in Spain, if I see rubbish, I take it away...if you only see a little rubbish, you know that people don't put the rubbish in the way, so if you see you take it...But here [Nepal], you see a lot, and I think it's...you prefer not to do anything...

\section{Young Spanish woman}

This statement is concerning because it directly correlates the will to behave environmentally friendly with the present environmental state of the Annapurna region. From such perspective, a thought of mind could sound, "If it does not 
make a big difference for the environment to take a piece of rubbish, why take it?" This correlates with the Theory of Planned Behavior (Ajzen, 1992) because a key element of this approach is to which extent people feel they can achieve the result they want. For some trekkers, it seems as if they simply do not feel their actions would create the results they want. As such, it seems that this specific trekking attitude correlates with another study in environmental issues; Anable, Lane and Kelay (2006) found that climate change is an issue within people's sphere of concern, but not within their perceived sphere of influence. From this perspective, it becomes a matter of the local authorities to ensure a clean region to make sure people want to preserve it like that.

The real concern consists in the apparent fact that the locals and tourist's perceived degree of environmental influence differs greatly. This causes a 'bystander effect' (Lowe et al., 2005) where mass paralysis of action takes place when people are confronted with something that demands intervention from each and every individual - in this case, protecting the fragile environment of the Annapurna region.

When we were on the bus from Kathmandu to Pokhara, we stepped out, and the first thing someone did was eating a banana and throwing all the lefties...the plastics on the floor...and we were like, well if you go to Nepal and you go hiking and you do it like that, that is rude, and I am not going to pick it up.

Young Dutch man

Even a seemingly environmentally aware Canadian woman appeared hopelessly affected by the current situation:

Yeah I think that, that, you know I have almost spent four months in Nepal and I start to feel that way, feel like, what's the point? Like, you just look and it's a total disaster in mess really everywhere as far as garbage and plastic. I have even had some Nepali friends and you know it's like, he finishes his drink and he just throws it in the ditch and I am like 'what are you doing?' and he just laughs...

Middle-aged Canadian woman

The main thread in these arguments is that they show a desperate environmental attitude that is based on the paradox of 'if they don't do anything, then I won't do anything'. However, simultaneously trekkers seem to consider themselves as very conscious when it comes to sustainable behavior. A main argument from many respondents seems to focus on the presence of an incorporated green awareness within trekkers:

Well you know, first of all, I think that trekkers are already nature lovers. So I think you are talking to a population that has a higher sense of nature and how to protect it 
A lot of trekkers even seemed to perceive their own environmental awareness to such an extent that they divided them into a separate tourism group compared to other tourists:

...people who live here in nature are more connected to nature...are feeling more responsible for nature, differently than people who go to Spain, to the beaches and drink a lot of beer.

Young Dutch man

\section{Or}

You're not going to get the British chaps who go and soak themselves in the sun in Costa Brava and eat, you know, ham and chips, and you know, they are not the kind of people that come here to buy the scenery.

\section{Young English man}

Apparently, there exists a high degree of self-satisfaction in trekkers' perception toward their pro-environmentalism. However, this self-perceived proenvironmentalism does not necessarily connect with the actual behavioral patterns, and when asked if it would make a difference to pick up rubbish, some respondents would honestly stress:

Absolutely makes a difference. Unfortunately I did not pick up one piece of rubbish, so I can't really say that everyone should. But I think absolutely it would make a difference, I think, yeah, for everyone...I saw more people than I did rubbish, so if everybody picked up one or two pieces I think it would be done... solved.

\section{Middle-aged American man}

\section{Or}

Everybody is talking about it, we are talking about it as well, but we are not really doing something against it. And as well at home, yeah, you try sometimes, you separate [rubbish]...but in fact you are not really doing something.

Young Swiss woman

Such statements made it clear to the research that awareness and intentions do not necessarily lead to action or a change in individual behavior. This fits with Owens (2000) critique that the level of a person's awareness may not significantly affect the person's behavior. This might give food for thought for tourism managers that primarily focus on the promotion of pro-environmentalism through guidelines, codes of conduct, information platforms etc. Making people aware of environmental problems is only an early step toward changing actual behavior. This researcher also stresses further focus on empowerment of 
trekkers, infrastructure development and voluntarism/participatory schemes that integrate trekkers and locals in larger environmental programs.

Trekking is good, trekking is bad and trekking is ugly In connection to trekkers' perception of the trekking industry, per se, there appeared to be quite a large difference in attitudes. The fieldwork found that trekking is seen as everything from an environmentally harming industry to a green industry. This indicates that trekking and its environmental impacts make up a 'grey area' within trekkers' frame of thoughts, which eventually makes it a complex matter to fully comprehend. When trekking is seen as a culture, and trekkers as products of this

culture, some trekkers seem to represent ethnocentric-like values, perceiving trekking as a better form of tourism than most other tourism types. Oppositely others will appear more relative toward the culture of trekking, apparently either disinterested or relaxed and unconcerned about its impacts. As a consequence, it seems that trekkers can be defined on a theoretical axis based upon their apparent 'cultural view', which is a person's perception of trekking and the actors connected to it (from a metaphorical point of view it represents how a person 'sees' trekking). Lacking more precise words, the research coined the two diametrical values on the continuum: 'cultural relativism' versus 'cultural ethnocentrism'.

\section{Commercializing the industry - An issue that divides trekkers}

The apparent demand for Western products has created an immense touristfocused consumerism in the midst of the Himalaya, which seemed to frustrate some trekkers who found such commercialization to be a 'cultural sell-out', whereas others appeared to understand the business-oriented side of the industry. However, all in all, most trekkers seem to understand the problematic and delicate balance between preservation and development of the region.

Some trekkers would display what could be coined a 'local lifestyle adapting' attitude toward trekking, rather than supporting the commercialization of the industry, in contrast to the people who take their Western comforts and needs with them while trekking.

You know here they have good apple juice, they have all kinds of tea, they have all food, rice, vegetables, they have everything. I think if you come here and you don't have all these products [Western commodities] jumping on your face, maybe...after three or four days you have new habits, habits of the trekkers in the middle of the Himalaya, not habits coming in from Paris or London. So I think it should be a very nice thing to cut all these products, and maybe...help the [local] people to have more products from the place.

Middle-aged Swiss man 
Interestingly, the upper statement actually encapsulates a main element of the research typology since it touches upon the contrast between 'habits of the trekker in the middle of the Himalaya' and 'habits coming from Paris or London'. Dressed in other word this is similar to what is argued throughout the analysis; a trekker's environmental attitudes seem to be influenced by the degree to which a trekker either adapts to local lifestyles or applies his/her own lifestyle to the trekking experience. This axis represents what trekkers actually 'do', and what can be observed.

...I mean the thing is that all trekkers are different. Some trekkers want to eat Dal Bhat [popular local dish] all the time, just like we were local. Other people want to have the Pringles and the Mars bars. And it depends very much on the mentality of the trekker, whether they can survive without the Mars bars and the Pringles.

\section{Middle-aged Scottish man}

As the research progressed, the researcher came to understand the importance of what trekkers seem to do (their observable lifestyle), which made up the basis of creating a theoretical axis that defines trekkers based upon how they appear to live their lives as a trekker. The two diametrical contrasts of 'adapting lifestyles' versus 'applying lifestyles' became the main values of this continuum, and would eventually be connected to the previously mentioned 'cultural view axis' to form the typology.

\section{Proposing a typology of environmental trekking rationalities}

The primary element of the typology is the interrelationship between the two axes represented by the bold horizontal and vertical lines, which can be seen as what trekkers respectively 'do' and 'see'. The vertical axis expresses the level of cultural immersion that a trekker accepts. That is, to which degree a trekker either applies his daily routine and lifestyle, or adapts the lifestyle and routines of locals while trekking. The horizontal axis represents the degree of 'cultural relativism' or 'cultural ethnocentrism' that a trekker expresses. In connection to this research, cultural relativism is typically expressed when trekkers do not see anything 'right' or 'wrong' with the local culture, but accept it for what it is without further thoughts about it. Oppositely, cultural ethnocentrism is when trekkers seem to make a clear division between ' $\mathrm{I}$ ' and 'them' and clearly express the 'rights' and 'wrongs' of the local society.

In practice, it is difficult to determine a given level of a trekker's attitudes, which is why it is important to stress that this is not the function of the typology. The typology merely illustrates ideal psychological rationalities that are based on the data analysis. According to this research, a trekker's environmental attitudes are strongly related to these two axes. As such, this research proposes that by 
taking into consideration these continuums, one can define what environmental rationality a trekker seems to represent.

The four ideal types that are deduced from this fundamental model have been coined with plain names that are meant to encapsulate the fundamental psychology of the given type. The specific names should therefore neither be understood literally in a larger social or political context, nor should they be criticized for their generalizing sound. They should simply be perceived as metaphors for different trekking rationalities.

Finally, it is important to stress that this typology is not a fundamental social truth or an applicable and wide-ranging theory. It singlehandedly represents the scope of this research field. This research argues that the proposed four ideal types cover the majority of trekkers in the region, and as such can be seen as being representative. However, trekkers might perceive themselves differently than what the researcher's observations and experiences identify.

The upper typology is based upon

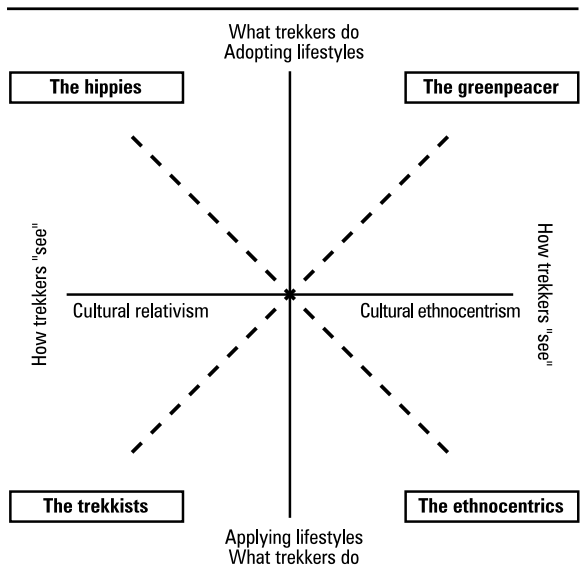

Figure 2: The typology of trekkers based on their environmental attitudes and awareness

the major issues that are found

to affect trekker's environmental profiles in a considerable manner, and is the result of the researcher's experiences within the fieldwork activities as well as the latter data analysis.

\section{Describing the rationalities}

The environmental 'hippies': A trekker characterized by his/her apparent disinterest in how the conservation area is managed and which guidelines apply. The emotional and intrinsic interplay between the trekker and the pristine surroundings and local culture is the pivotal part of this trekker. The intrinsic value that the basic lifestyle, which is similar to the locals, brings to this ideal type is the main driver for his/her environmental profile. He changes his life to become an integral part of the culture and nature, and respects nature for the sake of nature.

The environmental 'greenpeacer': This ideal type appears ethnocentric in the way that he/she 'sees' the surrounding culture, and seems interested in preserving the conservation area on the basis of what the person finds to be 
'the right' Annapurna. The profile is characterized by being skeptical about most issues concerning management of the conservation area and seems to blame the system and public authorities for the environmental problems. Another tendency within the 'greenpeacer' is that everything connected to commercialization and touristification of trekking is often regarded as negative per se. This type adapts to the lifestyle of the locals in the belief that the rural trekking lifestyle is the right trekking lifestyle.

The environmental 'ethnocentrics': Unlike the 'greenpeacer', the 'ethnocentrics' appear skeptical about the management and public/private bodies connected to the trekking industry. These arguments seem often based on some type of underlying cultural ethnocentrism and clear division between 'us' and 'them'. As a contrast to the 'greenpeacer', this ideal type prefers to take his/her daily habits and routines and apply them while trekking. Cultural distrust and the demand for Western comfort characterize this profile.

The environmental 'trekkists': This profile is contracted through the two words 'trekker' and 'tourist' based on this ideal type's apparent tourist-like behavior while trekking. 'Trekkists' seem characterized by their extrinsic motivation for trekking. This type of trekker does not seem to give much thought to the environmental state of the conservation area, but seems motivated by the personal enjoyment, social status and/or respect which his/her holiday might give in return. The 'trekkist' applies everyday life routines to his/her trekking behavior, and appears rather unconcerned with other issues apart from the personal enjoyment.

\section{Conclusions}

In line with the research question, this paper has identified a typology that encapsulates a number of main characteristics that seem to influence the environmental profile of a trekker. This research has provided the academic and professional industry with an illustrative proposal on how trekkers can be understood in connection to pro-environmental behavior and attitudes. This fundamental typology might be helpful for future academics and tourism professionals who look to investigate similar research fields. This research stresses that the typology should not be looked upon as a categorical tool which can be applied to a wide range of cases. The four ideal types that are presented here should be perceived as four case-based exploratory rationalities that open up for further analytical possibilities.

This research found that the four proposed ideal types of 'trekkists', 'hippies', 'ethnocentrics' and 'greenpeacers' represent the main environmental trekking rationalities within the Annapurna trekking industry. These profiles are constructed on the basis of two theoretical continuums. Firstly, what trekkers 
seem to actually 'do' (the observable behavior) which is expressed on an axis with the diametrical values; 'adapting lifestyles' and 'applying lifestyles'. Secondly, the profiles are identified on the basis of how they seem to perceive - and 'see' the trekking industry and the actors within it (the unobservable behavior). The interplay between 'doing' and 'seeing' makes up the heartbeat of the typology, and as such, works as the theoretical construction that forms the ideal types.

This paper argues that further research should look into the opposing management visions in connection to 'greening' the industry and commercializing the industry. The apparent tendency to promote pro-environmental trekking behavior, while simultaneously liberalizing the trekking market before the fundamental infrastructure (roads, waste management, local education etc.) is present, seems to be opposing visions. This research stresses the need for a better cooperation between public and private stakeholders in the Annapurna region.

Finally, the typology can be useful for tourism managers looking to improve their tourism activities. There exists considerable managerial benefit in understanding the psychology of the trekkers visiting the Annapurna conservation area, yet such understanding does not equal pro-environmental awareness. The findings from this paper must be converted to management actions, whether that is improving or redefining the present marketing and promotion programs with the proposed ideal types in mind; considering the level of commercialization of trekking; focusing on behavior-based development theories rather than awarenessbased ones, or something completely different is left to be concluded upon. This research has tried to pave the way for a better understanding of trekkers, which is found to be the essential component of the continuous vision of improving pro-environmental trekking behavior.

\section{References}

Ajzen, I. \& Driver, B. L. (1992). Application of the theory of planned behavior to leisure choice. Journal of Leisure Research, 24, 207-224.

Amendah, E., \& Park, J. (2008). Consumer Involvement and Psychological Antecedents on Eco-friendly Destinations: Willingness to Pay more. Journal of Hospitality Marketing \& Management, 17 (3), 262-283.

Anable, J., Lane, B. \& Kelay, T. (2006). An evidence base review of attitudes to climate change and transport. Report to the department for transport. London: HMSO. http:// www.yhub.org.uk/resources/Climate\%20Change\%20Micro\%20Site/publicattitudesCCandtransportbehaviour.pdf

Beedie, P. \& Hudson, S. (2003). Emergence of mountain-based adventure tourism. Annals of Tourism Research, 30 (3), 625-643.

Dingwall, R. (1997). Accounts, Interviews and Observation. In: Miller, G. \& Dingwall, R. (eds.) Context and method in qualitative research. Sage, London, 51-65. 
Fennel, D. A. (2000). Ecotourism: An introduction. Londres, Routledge.

Garratt, K. (1981). Sagarmatha National Park Management Plan. Unpublished report. Department of Land and Survey, Wellington, New Zealand.

Gellner, David N. \& Hirsch, E. (2001). Inside organizations: Anthropologists at work. Berg publishing.

Gurung, C. \& DeCoursey, M. (1994). The Annapurna Conservation Area Project: A pioneering example of sustainable tourism? In Cater, E. \& Lowman, G. (Eds.) Ecotourism: A sustainable option? (pp. 177-194). Chichester Wiley.

Gurung, C. \& DeCoursey, M. (1994). The Annapurna Conservation Area Project: A pioneering example of sustainable tourism? In Cater, E. \& Lowman, G. (eds.) Ecotourism: A sustainable option?, 177-194. Chichester Wiley.

Hines, J. M., Hungerford, H. R. \& Tomera, A. N. (1986). Analysis and synthesis of research on responsible environmental behavior: A meta-analysis. Journal of Environmental Education, 18, 1-8.

Jackson, T. (2005), 1st ed. Motivating Sustainable Consumption. London: DEFRA.

Korhonen, K. \& Lappalainen, A. (2004). Examining the environmental awareness of children and adolescents in the Ranomafana region, Madagascar. Environmental Education Research, 10 (2), 195-216.

Lee, W. \& Moscardo, G. (2005). Understanding the impact of Ecotourism Resort Experiences on Tourists' Environmental Attitudes and Behavioral Intentions. Journal of Sustainable Tourism, 13 (6), 546-565.

Lowe, T., Brown, K., Dessai, S., De Franca Doria, M., Haynes, K. \& Vincent, K. (2005). Does tomorrow ever come? Disaster narrative and public perceptions of climate change. Manchester: Tyndall Centre for Climate Change Research, Working Paper 72. http://www. uea.ac.uk/ e120782/papers/tdat.pdf2

Luo, Y. \& Deng, J. (2008). The New Environmental Paradigm and Nature-based Tourism Motivation. Journal of Travel Research, 46, 392-402.

Marshall, C. \& Rossman G. (1995). Recording, Managing and Analyzing Data. In Designing qualitative research, 2nd ed.. SAGE Publications, London, 108-119.

MCTA, (2004). Annual Statistics Report 2004. Kathmandu: Ministry of Tourism and Civil Aviation.

Miles, M. B. \& Huberman, M. (1994). Qualitative Data Analysis: An Expanded Sourcebook, 2nd ed., Sage Publications Inc.

Miller, G., Rathouse, K., Scarles, C., Holmes, K. \& Tribe, J. (2007). Public understanding of sustainable leisure and tourism. London: DEFRA.

Mishra, H. (1973). Conservation in Khumbu: The proposed Mt. Everest National Park. Unpublished report. Department of National Parks and Wildlife Conservation, Kathmandu. 
Moisander, J. (2007). Motivational complexity of green consumerism. International Journal of Consumer Studies, 31 (4), 404-409.

Musa, G., Hall, C. M. \& Higham, J. E. S. (2004). Tourism Sustainability and Health Impacts in High Altitude Adventure, Cultural and Ecotourism Destinations: A Case Study of Nepal's Sagarmatha National Park. Journal of Sustainable Tourism, 12 (4), 306-331.

NCC (National Consumer Council) \& SDC (Sustainable Development Commission (SDC) (2006). I will if you will - Towards sustainable consumption. Official report extracted from: www.sd-commission.org.uk

Nyaupane, Gyan P. \& Chhetri, N. (2009). Vulnerability to Climate Change of Nature-Based Tourism in the Nepalese Himalayas. Tourism Geographies, 11 (1), 95-119.

Nyaupane, Gyan P. \& Thapa, B. (2006). Perceptions of environmental impacts of tourism: A case study of ACAP, Nepal. International Journal of Sustainable Development \& World Ecology, 13 (1), 51-61.

Owens, S. (2000). Commentary: Engaging the public: Information and deliberation in environmental. Environment and Planning A, 32, 1141-1148.

Sacareau, I. (2009). Changes in environmental policy and mountain tourism in Nepal. Journal of Alpine Research, 97 (3), 1-13.

Sanjay, K. (2002). Tourism as a key to sustainable mountain development: The Nepalese Himalayas in retrospect. Unasylva, 53, 38-45.

Sanjay, K. (2000). Tourism in Protected Areas - The Nepalese Himalayas. Annals of Tourism Research, 27 (3), 661-681.

Stevens, S. (2003). Tourism and deforestation in the Mt Everest region of Nepal. The Geographical Journal, 169 (3), 255-277.

Pandey, M. B. (1994). International visitor attitudes to Sagarmatha (Mt Everest) National Park. Unpublished thesis. Licoln University, Canterbury, New Zealand.

Weber, K. (2001). Outdoor Adventure Tourism: A Review of Research Approaches. Annals of Tourism Research, 28 (2), 360-377.

Williams, P. \& Soutar, Geoffrey N. (2009). Value, satisfaction and behavioral intentions in an adventure tourism context. Annals of Tourism Research, 36 (3), 413-438.

Zurick, David N. (1992). Adventure Travel and Sustainable Tourism in the Peripheral Economy of Nepal. Annals of the Association of American Geographers, 82 (4), 608-628.

Özden, M. (2008). Environmental Awareness and Attitudes of Student Teachers: An Empirical Research. International Research in Geographical and Environmental Education, 17 (1), 40-55. 